\title{
Spinal versus General Anaesthesia for Laparoscopic Gynaecological Procedures: A Comparative Study of Haemodynamic Changes and Side Effects
}

\author{
Masum $A^{1}$, Islam $M^{2}$, Haque $M^{3}$, Ahmed $M^{4}$, Kalam $F^{5}$
}

\begin{abstract}
Introduction: Laparoscopic gynaecological procedures are conventionally done under general anaesthesia. Spinal anaesthesia is usually preferred only in patients where general anaesthesia is contraindicated. For laparoscopic gynaecological procedures sub arachnoid block is gaining popularity day by day as it is a good alternative to $G A$.
\end{abstract}

Objective: To compare haemodynamic changes and side effects between subarachnoid block (SAB) and general anaesthesia (GA) for lower abdominal laparoscopic gynaecological procedures.

Materials and Methods: A total number of sixty female patients were considered and divided equally into two groups as per American Society of Anesthesiologists (ASA) grade I and II. All patients underwent short duration $(<1 \mathrm{hr})$ laparoscopic gynaecological procedures. Group-I patients received lumber SAB and group-II patients received standard general anaesthesia using Propofol, Halothane and Fentanyl. Peri-operative heart rate, blood pressure, Electro-cardiogram (ECG) and Saturation of Oxygen $\left(\mathrm{SPO}_{2}\right)$ were monitored. Any intra operative and post operative side effects were also recorded and managed.

Results: Intra operative and post operative heart rate, systolic and diastolic blood pressure were significantly higher $(P<0.05)$ in group-ll. Preoperative, per operative and post operative mean blood pressure (MBP) were also significantly higher $(P<0.05)$ in group-II. During intraoperative period, the side effects in group-I were mainly discomfort and shoulder tip/neck pain and in group-II were hypertension and arrhythmia. Postoperative side effects were mainly postoperative nausea and vomiting (PONV).
Conclusion: Spinal anaesthesia using mixture of bupivacaine and fentanyl can be used as a safe alternative to GA for short duration gynaecological laparoscopic procedures with minimum haemodynamic alterations and reduced post operative side effects. To alleviate shoulder tip/neck pain or discomfort patient needs supplementary sedation and analgesia.

Key-words: Laparoscopic gynaecological procedure, Sub-arachnoid block, General anaesthesia, Hemodynamic parameters, Side effects.

\section{Introduction}

Laparoscopic surgery is a revolution in modern surgical technique. In recent years, laparoscopic surgery has become common clinical practice ${ }^{1}$. Laparoscopic procedures for gynaecological surgery are commonly applied under General anaesthesia $(\mathrm{GA})^{2,19,15}$. Regional anaesthesia is preferred only for patients who are at high risk under GA. GA with muscle relaxation and controlled ventilation is the preferred anaesthetic technique because it allows control of airways and ventilation, promotes uniform muscular relaxation and prevents aspiration ${ }^{17}$. Another reason for this popularity is that patients who are awake during such procedure do not tolerate the adverse effects of the pneumoperitoneum well ${ }^{3-6}$. Carbon dioxide $\left(\mathrm{CO}_{2}\right)$ is used as insufflating gas to create pneumoperitoneum. However, some centers have been using Sub Arachnoid Block (SAB) as their first preference in laparoscopic surgery for a long time $^{7,8}$. The advantages of a conscious patient and relatively uneventful recovery in one hand and the protection from potential complications of GA on the other hand were the main reason for selecting $S A B$ as first choice ${ }^{2,9}$. Regional anaesthesia in laparoscopic surgery offers some other advantages like

1. Lt Col Abdullah Masum, MBBS, MCPS, DA, FCPS (Anaesthesiology), Classified Specialist in Anaesthesiology, CMH, Dhaka 2. Brig Gen Md Saiful Islam(Retd), MBBS, MCPS, FCPS, Ex-Professor of Anaesthesiology, AFMC, Dhaka and Ex-Advisor Specialist in Anaesthesiology, $\mathrm{CMH}$, Dhaka 3. Brig Gen Mozibul Haque, MBBS, FCPS, Advisor Specialist in Anaesthesiology, CMH, Dhaka 4. Lt Col Masud Ahmed, MBBS, DA, FCPS, Classified Specialist in Anaesthesiology, CMH Dhaka 5. Lt Col Farzana Kalam, MBBS, MCPS, DA, FCPS, Classified Specialist in Anaesthesiology, CMH, Dhaka. 
decreased nausea/vomiting and less postoperative pain. The potential disadvantages are shoulder pain secondary to diaphragmatic irritation; discomfort and anxiety due to abdominal distension are incompletely alleviated using regional anaesthesia ${ }^{8-10,19}$. One of the most important problems with laparoscopic surgery under $S A B$ is inadequate relaxation of abdominal musculature but this rarely requires conversion to general anaesthesia ${ }^{11}$.

Laparoscopic surgery using regional anaesthesia often needs supplementation with intravenous sedation and analgesics because of increased anxiety, pain and discomfort. SAB may be a safe and effective technique for short duration gynaecological laparoscopic procedures provided that the patient is not put into extreme Trendelenburg position, the anaesthesia is supported with sedative and analgesics and abdominal pressure is kept between $8-10 \mathrm{~mm}$ $\mathrm{Hg}^{18}$. The length of surgery and surgeons experience is also important factor for the success of the surgeries ${ }^{7}$. In this study attempts have been taken to compare haemodynamic changes under $S A B$ with GA and to assess the feasibility of SAB for lower abdominal laparoscopic gynaecological procedures.

\section{Materials and Methods}

This was a prospective comparative study of randomly selected sixty patients of 15-45 years of age, female who underwent short duration ( $<1 \mathrm{hr}$ ) laparoscopic gynaecological procedures in Combined Military Hospital Dhaka from September 2012 to February 2013. The patients were divided into two groups by card sampling method with 30 patients in each group of ASA grade I and grade II. An informed written consent was taken from each patient. Group-I received lumber SAB and Group-II received GA with propofol, halothane and fentanyl. After pre-operative fasting for $6 \mathrm{hrs}$, with all aseptic precaution group-I patients were administered spinal anaesthesia in the sitting position using 27G Quincke Babcock spinal needles at $L_{2}-L_{3}$ inter space. A combination of $15 \mathrm{mg}$ (3ml) $0.5 \%$ hyperbaric bupivacaine and 25 microgram $(0.5 \mathrm{ml})$ fentanyl was administered in the lumbar subarachnoid space. As soon as the sensory block reached $T_{5}$ dermatome (level of sensory block was tested by pin prick stimulus) the patients were placed in dorsal lithotomy position with 10 degree head down tilt for a period of 10 minutes when the abdomen was prepared for verres needle insertion.
Pneumoperitoneum was created by insufflating $\mathrm{CO}_{2}$ gas. Intra abdominal pressure was adjusted to have a comfortable working field \{mean $8( \pm 2) \mathrm{cm} \mathrm{H}_{2} \mathrm{O}$ \}. Patient who complained of neck pain, shoulder tip pain or both and for anxiety and abdominal discomfort inj Midazolam $2 \mathrm{mg}$ and Tramadol 100 mg was administered slowly intravenously (IV). Patient who felt pain even after Midazolam and Tramadol administration, inj Ketamine $25 \mathrm{mg}$ was administered slowly. Bradycardia below $50 /$ min was managed by inj Atropine $0.6 \mathrm{mg}$. Hypotension at any time during or after surgery was managed by inj Ephedrine 5-10 mg IV intermittently up to a maximum $25 \mathrm{mg}$. In the post operative period pain was assessed using Visual Analogue Scale (VAS) and treated with inj Diclofenac sodium $50 \mathrm{mg}$ intramuscularly.

In group-II patients standard general anaesthesia was provided. Metoclopramide $10 \mathrm{mg}$, Ranitidine 50 $\mathrm{mg}$ and Fentanyl 1 microgram/kg was administrated intravenously (IV) 15 minutes before operation. Induction was done with Propofol, intubation with vecuronium bromide and anaesthesia was maintained with Nitrous oxide $(60 \%)$, oxygen $(40 \%)$ \& halothane 0.5 Minimum Alveolar Concentration (MAC). Intra operative analgesia was provided by short acting opioid-Fentanyl. Neuromuscular blockade was reversed on completion of surgery with Neostigmine methyl sulphate and Atropine sulphate. Base line heart rate, blood pressure and respiratory rates were noted in all patients. In both groups, continuous ECG, heart rate, blood pressure and $\mathrm{SPO}_{2}$ were recorded every 5 minutes interval during the procedures. In the post operative period continuous ECG, heart rate, blood pressure and $\mathrm{SPO}_{2}$ were recorded at 10 minutes interval. Any intra operative and post operative complications were recorded and managed accordingly. All results were expressed as mean \pm standard deviation (SD) or in frequencies (percentage) as applicable. All results were compiled and was analyzed using Student's 't' test.

\section{Results}

Demographic profiles of the patients in the groups were comparable (Table-I). Intra operative and post operative heart rates were significantly higher $(P<0.05)$ in group-II (Table-II). Intra operative and post operative systolic blood pressure (SBP) were 
also significantly higher $(\mathrm{P}<0.05)$ in group-II (Table-III). Intra operative and post operative Diastolic blood pressure $(\mathrm{DBP})$ were also significantly higher $(\mathrm{P}<0.05)$ in group-II (Table-IV). Pre-operative, per operative and post operative mean blood pressure (MBP) were also significantly higher $(P<0.05)$ in group-II (Table-V).

During intraoperative period, few side effects were observed in both groups (Figure-1). In group-I, these were mainly discomfort and shoulder tip /neck pain and in group-II, hypertension and arrhythmia. The incidences of intra operative complications in SAB group were little higher than GA grouped but the incidences of post operative complication were significantly higher in GA grouped. Complications after the procedures (Table-VI) were mainly post operative nausea and vomiting (PONV) and the incidence of which was significantly higher in group-II. No patient had urinary retention or post dural puncture headache in the post operative period.

Table-I: Patient's demographic characteristics between the study groups ( $n=30$ patients for each group)

\begin{tabular}{|l|c|c|c|}
\hline Characteristics & Group-I & Group-II & P \\
\hline Age $($ years $)$ & $26.20 \pm 4.55$ & $26.03 \pm 4.58$ & 0.883 \\
\hline Height $(\mathrm{cm})$ & $155.97 \pm 4.05$ & $155.23 \pm 2.84$ & 0.404 \\
\hline Weight $(\mathrm{kg})$ & $59.72 \pm 6.36$ & $57.80 \pm 6.78$ & 0.213 \\
\hline ASA-I & $63.33 \%$ & $70.00 \%$ & \\
ASA-II & $36.67 \%$ & $30.00 \%$ & \\
\hline
\end{tabular}

Values are expressed as mean \pm SD. Significant $P$ $<0.05$ (between two groups) for age, height, body weight, ASA grade-I \& II; Student's 't' test was done to find out the difference between groups.

Table-II: Comparison of heart rate at different time between the study groups ( $n=30$ patients in each group)

\begin{tabular}{|l|c|c|c|}
\hline Period & Group-I (n=30) & Group-II (n=30) & P \\
\hline Pre operative & $79.47 \pm 10.52$ & $80.80 \pm 7.75$ & 0.617 \\
\hline Per operative & $71.00 \pm 4.00$ & $77.00 \pm 6.00$ & 0.010 \\
\hline Post operative & $74.00 \pm 4.00$ & $80.00 \pm 7.89$ & 0.001 \\
\hline
\end{tabular}

Values are expressed as mean $\pm S D$. Significant $P$ $<0.05$ (between two groups) for heart rate changes in both groups in pre-operative, per operative and post operative period; Student's ' $t$ ' test was done to find out the difference between groups.
Table-III: Comparison of systolic blood pressure at different time between the study groups $(n=30$ patients in each group)

\begin{tabular}{|l|c|c|c|}
\hline Period & Group-I (n=30) & Group-II (n=30) & P \\
\hline Pre operative & $120.93 \pm 12.19$ & $122.1 \pm 8.53$ & 0.673 \\
\hline Per operative & $99.00 \pm 2.00$ & $111.00 \pm 7.00$ & 0.000 \\
\hline Post operative & $105.00 \pm 7.00$ & $116.00 \pm 7.10$ & 0.000 \\
\hline
\end{tabular}

Values are expressed as mean $\pm S D$. Significant $P$ $<0.05$ (between two groups) for systolic blood pressure changes in both groups in pre operative, per operative and post operative period; Student's ' $t$ ' test was done to find out the difference between groups.

Table-IV: Comparison of diastolic blood pressure at different time between the study groups $(n=30$ patients in each group)

\begin{tabular}{|l|c|c|c|}
\hline \multicolumn{1}{|c|}{ Period } & Group-I (n=30) & Group-II (n=30) & P \\
\hline Pre operative & $67.80 \pm 7.02$ & $69.17 \pm 5.87$ & 0.443 \\
\hline Per operative & $53.00 \pm 2.00$ & $56.00 \pm 1.00$ & 0.000 \\
\hline Post operative & $63.00 \pm 3.00$ & $67.00 \pm 3.22$ & 0.000 \\
\hline
\end{tabular}

Values are expressed as mean $\pm S D$. Significant $\mathrm{P}<0.05$ (between two groups) for diastolic blood pressure changes in both groups in preoperative, per operative and post operative period; Student's ' $t$ ' test was done to find out the difference between groups.

Table-V: Comparison of mean blood pressure at different time between the study groups $(n=30$ patients in each group)

\begin{tabular}{|l|c|c|c|}
\hline Period & Group-I (n=30) & Group-II (n=30) & P \\
\hline Pre operative 0p & $82.33 \pm 9.39$ & $87.77 \pm 10.41$ & 0.000 \\
\hline Per operative 0p & $69.00 \pm 4.00$ & $75.00 \pm 6.01$ & 0.002 \\
\hline Post operative 0p & $77.15 \pm 6.27$ & $83.00 \pm 9.22$ & 0.001 \\
\hline
\end{tabular}

Values are expressed as mean $\pm S D$. Significant $P$ $<0.05$ (between two groups) for mean blood pressure changes in both groups in pre operative, per operative and post operative period; Student's ' $\mathrm{t}$ ' test was done to find out the difference between groups.

Table-VI: Side effects after the procedure between the study groups ( $n=30$ patients in each group)

\begin{tabular}{|l|c|c|c|}
\hline Complications & Group-I (n=30) & Group-II (n=30) & Total Patients \\
\hline PONV & $6(20 \%)$ & $15(50 \%)$ & $21(35.0 \%)$ \\
\hline Hypotension & $3(10 \%)$ & $1(3.33 \%)$ & $4(6.67 \%)$ \\
\hline Shivering & $1(3.33 \%)$ & $1(3.335)$ & $2(3.33 \%)$ \\
\hline
\end{tabular}




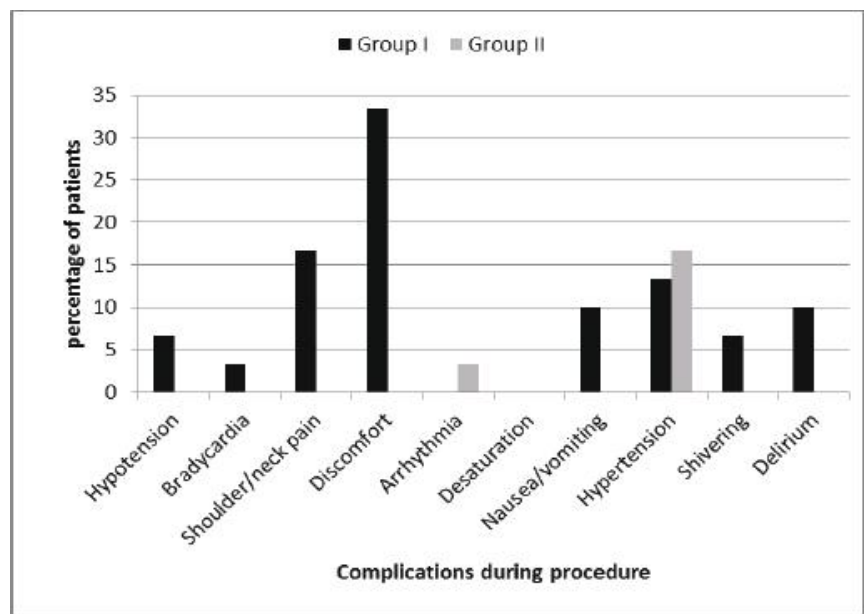

Fig-1: Complications during intra operative period between the groups

\section{Discussion}

Laparoscopic gynaecological procedures are conventionally done under general anaesthesia ${ }^{14}$. Spinal anaesthesia is usually preferred in patients where general anaesthesia is contraindicated. Spinal anaesthesia is routinely deferred for laparoscopic surgeries because of its suppressive effects on the respiratory muscle function under increased abdominal pressure. Mulroy et $\mathrm{al}^{3,16}$ has observed that performing laparoscopic surgery under regional anaesthesia carries many advantages over general anaesthesia like early recovery, reduced PONV, lower post operative pain, shorter hospital stay etc.

This study was to find out haemodynamic alterations under spinal anaesthesia in comparison to GA and to observe the side effects of $S A B$ for laparoscopic gynaecological procedures. In this study, patients of both group showed a significant decrease in heart rate, systolic blood pressure, diastolic blood pressure and mean arterial blood pressure during intra operative period from the baseline values. These changes are attributed to the sympathetic blockade and decreased afterload after establishing $S A B$. Yasser et $a^{12}$ in their study the feasibility of spinal anaesthesia with sedation for laparoscopic procedure found that changes led ultimately to patient's haemodynamic stabilization secondary to the increase in ejection fraction and cardiac output as confirmed. In addition to SAB related hypotension, the pneumoperitoneum induced rise in intra abdominal pressure could be another cause for the persistence of hypotension. In the post operative period in both groups heart rate, systolic blood pressure, diastolic blood pressure and mean blood pressure increased from intra operative period possibly because of changes in peripheral vascular resistance and relative increase in cardiac index, effects that were maintained thereafter.

In this study, a significant number (50 percent) of patients experienced discomfort of which $5(16.67 \%)$ patients experienced shoulder tip/neck pain. A higher incidence of shoulder tip pain has been reported by Minai et $\mathrm{al}^{13}$. This was attributed to the physical and chemical stimulation of the diaphragm by pneumoperitoneum. In contrast to this study, Minai et $\mathrm{al}^{13,17}$ stated that most of the patients in their study experienced severe agitation often accompanied with chest pain. They related these findings to the lack of efficient sedation or low level of block. No patient had urinary retention or post dural puncture headache in the post operative period. This contradicts with the study of Vaghadia"; who observed 38 percent of all patients developed headache in the post operative period.

\section{Conclusion}

This prospective study between subarachnoid block and general anaesthesia concludes that spinal anaesthesia using mixtures of Bupivacaine along with Fentanyl can be used as a safe alternative to general anaesthesia for short duration gynaecological laparoscopic procedures with minimum haemodynamic alterations, no respiratory embarrassment even during pneumoperitoneum and reduced post operative complications. But for the experience of shoulder tip Ineck pain or discomfort by the patient requires supplementary sedation and analgesia.

\section{References}

1. Alexander IJ. Pain after laparoscopy. British Journal of Anaesthesia 1997; 79:369-78.

2. Kuramochi k, Osuga Y, Yano T. Usefulness of epidural anesthesia in gynecologic laparoscopic surgery for infertility in comparison to general anesthesia. Surg Endosc 2004; 18:847-51. 
3. Mulroy MF, Spinal anaesthesia for outpatients: appropriate agents and techniques. Clin Anesth 1995; 7:622-7.

5. Pavlin DJ, Rapp SE, Polissar NL. Factors affecting discharge time in adult outpatients. Anesth Analg 1998; 87:816-26.

6. Vaghadia H. Spinal anaesthesia for outpatients: controversies and new techniques. Can J Anesth 1998; 45:64-70.

7. Murphy AA, Nager CW, Wujek JJ. Operative laparoscopy versus laparotomy for the management of ectopic pregnancy: A Prospective trial. Fertil Steril 1992; 57:1180-5.

8. Gerges FJ, Kanazi GE, Jabbthis-Khthisy SI. Anesthesia for laparoscopy: A review. J Clin Anesthesia 2006; 18:67-78.

9. Sinha R, Gurwara KA, Gupta CS. Laparoscopic Surgery using Spinal Anesthesia. JSLS 2008 AprJun; 12(2):133-8.

10. Pursnani KG, Bazza $Y$, Calleja $M$, et al. Laparoscopic cholecystectomy under epidural anesthesia in patients with chronic respiratory disease. Surg Endosc 1998; 12:1082-4 [PubMed].

11. Aldrete JA. The post-aneasthesia recovery score revisited. J Clin Anesth 1995; 7:89.

12. Ali $Y$, Elmasry NM, Negmi $H$, et al.The feasibility of spinal anaesthesia with sedation for laparoscopic general abdominal procedures in moderate risk patients. MEJ ANESTH 2008; 19(5):1027-38.
13. Minai H, Yamada K, Tashiro K. Anesthesia management for awake laparoscopic surgery for ectopic pregnancy in a patient with heterotopic pregnancy. Masui Nov2005; 54(11):1313-4.

14. Wodlin BN, Nilsson L, Carlsson $P$, et al. Cost-effectiveness of general anesthesia vs spinal anesthesia in fast-track abdominal benign hysterectomy. American J of Obs and gynecology 2011; 205(4):326 e1-326e7.

15. Saraswat N, Kumar a, Mishra A, et al. The comparison of proseal laryngeal mask airway and endotracheal tube in patients undergoing laparoscopic surgeries under general anaesthesia. Indian Anaesth 2011; 55:129-34.

16.Daniel M, Elia N, Van $\mathrm{KH}$, et al. Impact of Epidural Analgesia on Mortality and Morbidity after surgery: Systematic Review and Meta-analysis of Randomized Controlled Trails. Ann Surg 2014; 259:1056-67.

17. Rawal N. Epidural technique for postoperative pain: gold standard no more? Reg Anesth Pain Med. 2012; 37:310-7.

18. Kuramochi K, Osuga Y, Yano t, et al. Usefulness of epidural anesthesia in gynecologic laparoscopic surgery for infertility in comparison to general anesthesia. Surg Endosc 2004; 18:847-50.

19. Labato EB, Palge GB, Michelle $M$, et al. Pneumoperitoneum as a Risk Factor for Endobronchial intubation during laparoscopic Gynecologic Surgery. Anesthesia and Analgesia 1998; 86(2):301-3. 